\title{
The Use of Probabilistic Networks to Evaluate Passive Fire Protection Measures in Hospitals
}

\author{
RAYMOND J. CONNOLLY \\ Fire Safety Engineering Solutions Ltd., \\ Kinetic House \\ Theobald Street \\ Borehamwood, WD6 4PJ, UK \\ DAVID A. CHARTERS \\ NHS Estates \\ 1 Trevelyan Square \\ Boar Lane, Leeds, LS1 6AE, UK
}

\begin{abstract}
This paper describes how probabilistic networks may be used to evaluate the effectiveness of different passive fire protection measures in contributing to fire safety in hospitals. In particular, study is made of the benefit of basic fire safety management, fire-resisting doorsets and the influence of self-closing devices. It is concluded that probabilistic networks offer a useful tool which can inform decisions regarding the cost benefit of fire protection measures.
\end{abstract}

KEY WORDS Probabilistic networks, fire spread, fire doors

\section{INTRODUCTION}

Much effort has been devoted by fire safety scientists to understanding the growth and development of a fire within the room of origin. The results of such work also allow some understanding as to how fire spreads from its room of origin to adjacent spaces. However, fire spread beyond the room of origin is a strongly probabilistic phenomenon and the utility of predictive deterministic models depends on the quantitative treatment employed for the stochastic aspects of the process. While a number of stochastic treatments have been developed [1], this paper examines how fire spread can be modelled through probabilistic networks [2] and how network analysis techniques can be applied to address fundamental fire safety issues.

Fire safety is one of the greatest challenges facing the designers and operators of healthcare premises. This is particularly true where patients are highly dependent on staff, eg the elderly, mentally ill, those in intensive therapy, theatres ...etc. The lack of alertness, lack of mobility and high dependency on fixed equipment of these patients have obvious implications for their fire safety in the event of a fire. Furthermore, the proportion of highly dependent patients in hospitals is likely to increase with greater life expectancy and advances in health treatment. The UK standard for hospital fire safety FIRECODE [3] was developed to address these issues and comprises a suite of documents providing comprehensive guidance on fire safety within 
healthcare premises. FIRECODE's fire safety strategy is based primarily on the avoidance of fire. However, in the event of fire there should be means for rapid detection, containment and control, supported by reliable and well rehearsed procedures for removing patients to places of safety. The final aspect of the strategy involves the concept of 'progressive horizontal evacuations' where patients are moved away from the fire and behind fire-resisting compartment walls on the same level as the fire.

Clearly, the various levels of compartmentation play a significant role in the process of progressive horizontal evacuation [4]. Generally, each department or ward should be enclosed by a compartment providing one hour's fire resistance. Similarly, each floor should also provide one hour's fire resistance. Within each one hour compartment there may also be two other types of compartmentation; sub-compartments and fire hazard rooms.

Sub-compartments divide the department of ward into two or three 'protected areas' enclosed by half hour fire-resisting construction. This is intended to allow staff in the department of fire origin to move patients from the sub-compartment of fire origin to adjacent sub-compartments or compartments as the first stage of progressive horizontal evacuation. Fire hazard rooms are intended to separate those parts of departments or wards containing significant fire load and/or ignition sources (eg kitchens, stores, day rooms etc.) from the bedded areas [5].

One of the most crucial elements in the success of progressive horizontal evacuation is the reliability and performance of the compartmentation. Historical data indicates that the most crucial components in provision of compartmentation are fire doors [6,7]. Doors can have one or more functions in a building including; access, security, privacy, noise reduction etc. as well as fire safety if appropriate. Thus several types of door in a hospital may also form part of a fire compartment and it is important that they perform their function in 'normal conditions' and in the event of fire.

The variables associated with fire doors include their fire resistance rating and the type of closing mechanism used. Fire ratings are usually considered to be notionally 'zero', half hour or one hour. However, the 'zero' rating should more accurately be interpreted as 'not tested'. In fact, most well fitting doors are capable of resisting fire for some duration. While, this could be anything up to 20 minutes for solid door leaves, doors incorporating glazing panels are more likely to fail in about 5 minutes. Fire doors may be single or double acting and may be selfclosing, free or held open on detents.

The following analysis uses an existing approach to modelling fire spread through probabilistic networks [2] in order to evaluate the importance of these variables in fire door specification. The approach demonstrates how the most reliable and cost-effective fire door specification can be determined for specific applications. 


\section{Construction of a space graph to represent the physical problem}

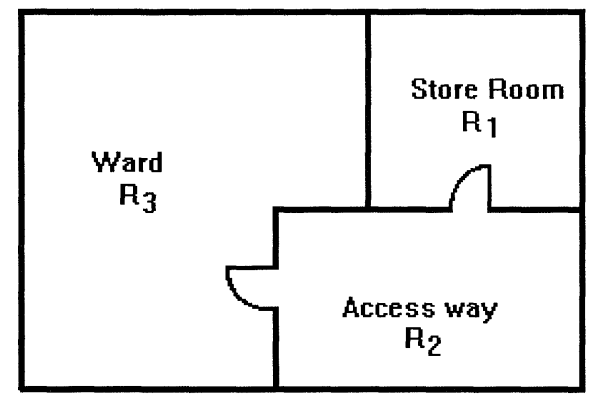

Figure 1 shows the layout of a typical hospital ward. The ward consists of 3 distinct fire compartments; a store room (1), an access way (2) and a ward (3). It is assumed that the store room is a fire hazard room and as required by FIRECODE [3] is bounded by half hour fire-resisting construction. It is further assumed that the fire begins in the store room.

Figure 1. Layout of typical hospital ward

As passive measures such as fire doors are designed to protect against fully developed fires, one of the key stages in fire spread is the occurrence of flashover in the fire space. A fire spread mechanism is hypothesised as follows; given the occurrence of flashover in the store room (which is denoted by $1^{*}$ ), the subsequent failure of the door between the store and the access way (2) allows the access way itself to become the scene of a fire which in time becomes fullydeveloped $\left(2^{*}\right)$. This in turn causes failure of the door into the ward (3) and threatens its occupants. An alternative scenario is that a fully-developed fire in the store $\left(1^{*}\right)$ causes failure of its fire-resisting boundaries and poses an immediate threat to the occupants of the ward (3).

In Figure 2, the floor plan of Figure 1 has been combined with the above fire scenarios to form a graph. Each link in the graph represents a possible route of fire spread, so for example the direct link from the store to the ward represents fire breaching the wall between them.

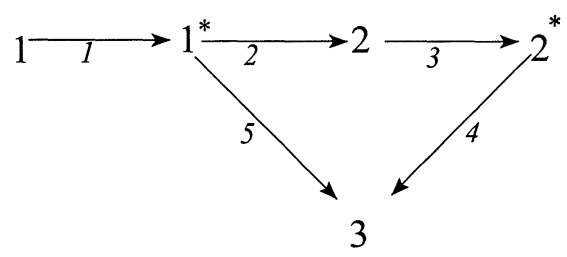

Figure 2. Probabilistic network representing scenario 


\section{Transformation of space graph into a probabilistic network}

Figure 2 illustrates using links the routes for fire spread. There are two types of links corresponding firstly to fire growth within a space and secondly to fire breaching a spatial boundary. To convert the space graph into a probabilistic network, each link is assigned a pair of numbers $\left(p_{i}, t_{i}\right)$ representing respectively the probability that the fire will go through link and the time it will take to do so.

In the case where a link represents the breach of a spatial barrier, $t_{i}$ is assigned the value of the fire resistance rating of the barrier. This fire resistance rating will have some probability associated with it. In the case of a solid wall, for example, probabilistic treatment may be necessary to reflect aspects such as random differences between the wall construction and that construction actually tested, variability in fire test results etc. In the case of a door, the probability could reflect the fact that the door may be open, in which case its fire resistance is truly zero. Unfortunately, the practicalities of obtaining such probabilistic data can be inhibitive.

Where links represent fire growth within a room, $t_{i}$ represents the time to flashover and $p_{i}$ the probability of flashover occurring. Both factors could be determined using a combination of deterministic and stochastic models. A generalised probabilistic network is shown in Figure 3.

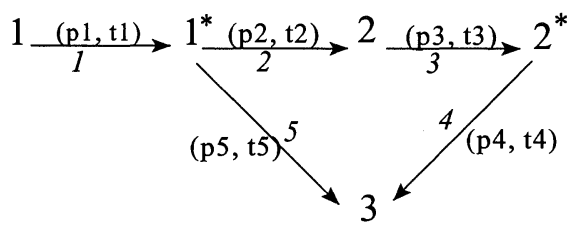

Figure 3. Generalised probabilistic network

\section{Network analysis}

Once the probabilistic fire spread network has been established, the next step is to determine some means of measuring how long a fire would take to spread from the store room to the ward. The measure chosen is "expected shortest time". In PERT [9] analyses, the objective is typically to find the longest path through a network. However, for the fire problem Williamson and Ling [2] have evolved a network analysis technique developed by Mirchandani [10] for use in determining the shortest path through the network. A full description of the procedure is beyond the scope of this paper, but in essence the technique involves transformation of the network into an equivalent network of source and sink nodes. It is assumed that the fire travelling along the links will always follow the shortest operating path. The equivalent network has the properties that each link has a Bernoulli probability of success, the link travel times are deterministic and the expected shortest path times in the equivalent network is equal to those in the original 
network. Given a link $L_{i}$ which has a discrete probability distribution $f(t)$ where

$$
\begin{array}{cl}
f(t)=s_{m} \text { for } t=t_{m} & m=1,2, \ldots \ldots, r \\
s_{\infty}=1-\sum s_{i} & t=\infty
\end{array}
$$

and $t_{m}$ is the travel time for the links, $m=1,2, \ldots, r$, the equivalent network is generated by replacing each link with $r$ parallel links each of which has a probability of success $p_{m}$ and associated travel time $t_{m}$ defined as follows:

$$
\begin{gathered}
p_{s}=s_{1} \\
p_{m}=\frac{s_{m}}{1-\sum s_{i}} \quad m=2,3, \ldots, r .
\end{gathered}
$$

To evaluate the expected shortest path, it is necessary first to find all the possible paths between the source and sink nodes, ie between initial and final states. Williamson and Ling [2] suggested that the Mc Naughton-Yamada algorithm is appropriate. If $P_{1}, P_{2}, \ldots, P_{n}$ represent all paths between the source and sink, then the time for travel between source and sink over any one path is simply the summation of the individual link times on the path, and the probability of that path being used is the product of the component link probabilities. It can be shown that the probability $Q_{m}$ that the fire will spread from the source to the sink along one or more of the paths $P_{1}, P_{2}, \ldots, P_{m}$ is given by;

$$
Q_{m}=Q_{m-1}+P_{m}\left[1-U_{m}\right]
$$

where $P_{m}$ is the product of the probabilities of each link on the path and $U_{m}$ is the conditional probability that spread occurs along at least one of the paths prior to the $m^{\text {th }}$ path given that spread occurs along the $m^{\text {th }}$ path itself. Given that $U_{0}=U_{l}=Q_{0}=0$ then $U_{m}$ may be determined recursively from;

$$
U_{m}=\left(Q_{m-1}\right)_{P_{m / 1}}
$$

where $P_{m / 1}$ indicates that all the link probabilities associated with path $P_{m}$ are set equal to unity in a subscript expression. The probability $R$ of the source connecting with the sink node and hence that of fully developed fire spreading between the initial and final spaces is given by;

$$
R=P_{1}+P_{2}\left(1-U_{2}\right)+\ldots \ldots+P_{n}\left(1-U_{n}\right)
$$

and the expected shortest time $T$ for this event to occur is given by; 


$$
T=\frac{T_{1} P_{1}+T_{2} P_{2}\left(1-U_{2}\right)+\ldots \ldots+T_{n} P_{n}\left(1-U_{n}\right)}{R}
$$

\section{Assembly of a datum probabilistic network for study of hospital fire safety}

A datum scenario has been decided against which various alternative fire safety strategies will be compared. The objective of fire protection measures is to prevent a fire starting in the store room from spreading to the ward. For the datum case, a minimal level of protection is assumed. The wall separating the store from the ward is 30 minutes fire resisting. However, the door to the store room and to the ward are not specified as fire-resisting and as such are considered to offer a fire resistance of only 5 minutes. Further, it is assumed that there is a $50 / 50$ chance of these doors being open, in which event their fire resistance would clearly be zero. For the purposes of this paper the time to flashover need not be specified. The probability of flashover $P_{\text {flashover }}$ has been assumed as

$$
P_{\text {flashover }}=1-P_{\text {first item }}
$$

where $P_{\text {frst item }}$ is the probability that the fire being confined to the first item ignited. Appropriate data is available in FIRECODE [3] and is summarised in Table 1.

Table 1. Probability of fire being confined to first ignited item [3]

\begin{tabular}{|c|c|}
\hline Room Type & $\mathbf{P}_{\text {first item }}$ \\
\hline Store & 0.07 \\
\hline Access way & 0.71 \\
\hline Ward & 0.07 \\
\hline
\end{tabular}

The equivalent probabilistic network for the datum case is shown in Figure 4 and the relevant calculations summarised in Table 2 .

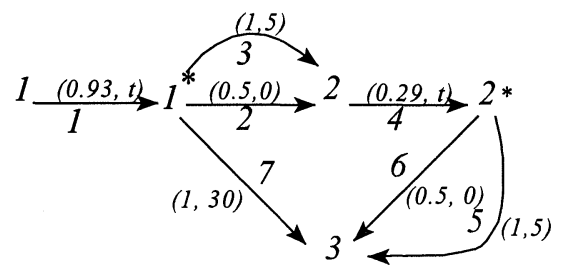

Figure 4. Probabilistic network for datum setup 
Table 2. Probabilistic network calculations for datum setup

\begin{tabular}{|c|c|c|c|c|c|c|}
\hline $\boldsymbol{i}$ & Path & $\boldsymbol{T}_{\boldsymbol{i}}$ & $\boldsymbol{P}_{\boldsymbol{i}}$ & $\boldsymbol{U}_{\boldsymbol{i}}$ & $\boldsymbol{P}_{\boldsymbol{i}}\left(\mathbf{I}-\boldsymbol{U}_{\boldsymbol{i}}\right)$ & $\boldsymbol{T}_{\boldsymbol{i}} \boldsymbol{P}_{\boldsymbol{i}}\left(\mathbf{I}-\boldsymbol{U}_{\boldsymbol{i}}\right)$ \\
\hline $\boldsymbol{1}$ & $1-2-4-6$ & $2 \mathrm{t}$ & 0.067 & 0 & 0.07 & $0.13 \mathrm{t}$ \\
\hline 2 & $1-2-4-5$ & $2 \mathrm{t}+5$ & 0.014 & 0.5 & 0.07 & $0.13 \mathrm{t}+0.34$ \\
\hline 3 & $1-3-4-6$ & $2 \mathrm{t}+5$ & 0.014 & 0.5 & 0.07 & $0.13 \mathrm{t}+0.34$ \\
\hline 4 & $1-3-4-5$ & $2 \mathrm{t}+10$ & 0.275 & 0.75 & 0.07 & $0.13 \mathrm{t}+0.67$ \\
\hline 5 & $1-7$ & $\mathrm{t}+30$ & 0.930 & 0.29 & 0.71 & $0.66 \mathrm{t}+19.81$ \\
\hline
\end{tabular}

From Equation 6, the expected shortest time for fire to spread from the store to the ward with the datum level of fire protection is;

$$
t_{\text {shortest }}=1.22 t_{\text {flashover }}+21.6 \text { minutes }
$$

As one would expect, delaying the onset of flashover is beneficial in reducing the propensity of fire spread. The model suggests that fire spread is likely to take at least 21.6 minutes given the nature of the fire precautions defined in the datum case. At this stage, it is worth emphasising that the model is only considering the spread of fully developed fires and no inferences may be drawn regarding the spread of smoke and hot gases.

\section{EVALUATION OF VARIOUS FIRE PROTECTION MEASURES}

\section{(i) Fire safety management - Locking of store room door}

A sensible fire precaution may be to lock the door of the store room shut. This removes the possibility of the door being open and guarantees at least 5 minutes separation between the store and surrounding spaces. The probabilistic network changes only slightly from that shown in Figure 4, in that link 2 is simply removed. This reduces the number of potential paths through the network to 3 and simplifies the network calculations as shown in Table 3.

Table 3. Probabilistic network calculations for setup with locked store room door

\begin{tabular}{|c|c|c|c|c|c|c|}
\hline $\boldsymbol{i}$ & $\boldsymbol{P a t h}$ & $\boldsymbol{T}_{\boldsymbol{i}}$ & $\boldsymbol{P}_{\boldsymbol{i}}$ & $\boldsymbol{U}_{\boldsymbol{i}}$ & $\boldsymbol{P}_{\boldsymbol{i}}\left(\mathbf{I}-\boldsymbol{U}_{\boldsymbol{i}}\right)$ & $\boldsymbol{T}_{\boldsymbol{i}} \boldsymbol{P}_{\boldsymbol{i}}\left(\mathbf{l}-\boldsymbol{U}_{\boldsymbol{i}}\right)$ \\
\hline$I$ & $1-2-3-4$ & $2 \mathrm{t}+5$ & 0.135 & 0 & 0.14 & $0.27 \mathrm{t}+0.68$ \\
\hline 2 & $1-2-3-5$ & $2 \mathrm{t}+10$ & 0.270 & 0.5 & 0.14 & $0.27 \mathrm{t}+1.35$ \\
\hline 3 & $1-6$ & $\mathrm{t}+30$ & 0.930 & 0.29 & 0.66 & $0.66 \mathrm{t}+19.8$ \\
\hline
\end{tabular}


The expected shortest time for fire to spread from the store to the ward in this case becomes;

$$
t_{\text {shortest }}=1.29 t_{\text {flashover }}+23.5 \text { minutes }
$$

(ii) Fire safety management - Locking of store room door and fitting self-closing device on ward door

In addition to locking the store, fitting a self-closer to the ward door would have reduce its probability of being open, $\delta_{\text {open }}$, in the event of a fire. The probabilistic network is largely similar to that shown in Figure 4 with the only change being to the probability on link 6, which changes from 0.5 (based on the initial 50/50 assumption) to the variable $\delta_{\text {open }}$. The analysis remains similar and concludes an expected shortest time for fire to spread from the store to the ward of;

$$
t_{\text {shortest }}=1.29 t_{\text {flashover }}-1.35 \delta_{\text {open }}+24.2 \text { minutes }
$$

While this conclusion confirms the intuitive notion that introducing a self-closing device to the ward door increases the expected time of fire spread, quantification of the maximum benefit shows it to be surprisingly low - in the order of $5 \%$.

\section{(iii) Structural precautions - Increasing the fire resistance rating of doors}

If the fire resistance rating of the store room door is upgraded to 30 minutes and the door is locked shut then immediately it is clear that $t_{\text {shortest }}=t_{\text {flashover }}+30$ minutes, with the specification and performance of the ward door being irrelevant.

In the case, where the store room is not locked, the nature of the ward door becomes an influence on the overall level of safety. If it is assumed that the store room door is placed on a self-closing device and the ward door is unspecified, ie 5 minutes fire resistance with a 50/50 chance of being open, the network is shown in Figure 5 and the relevant calculation summarised in Table 4.

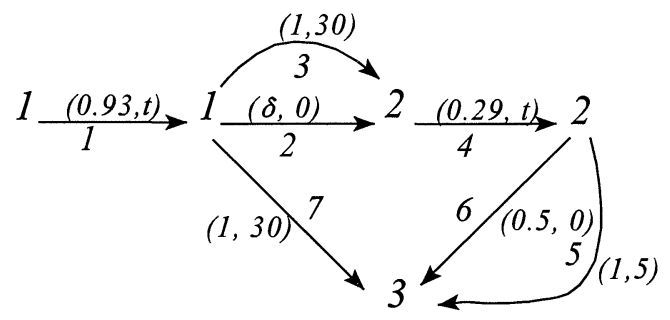

Figure 5. Network for fire door on self closer 
Table 4. Probabilistic network calculations for fire resisting store room door on self closer

\begin{tabular}{|c|c|c|c|c|c|c|}
\hline $\boldsymbol{i}$ & $\boldsymbol{P a t h}$ & $\boldsymbol{T}_{\boldsymbol{i}}$ & $\boldsymbol{P}_{\boldsymbol{i}}$ & $\boldsymbol{U}_{\boldsymbol{i}}$ & $\boldsymbol{P}_{\boldsymbol{i}}\left(\boldsymbol{I}-\boldsymbol{U}_{\boldsymbol{i}}\right)$ & $\boldsymbol{T}_{\boldsymbol{i}} \boldsymbol{P}_{\boldsymbol{i}}\left(\boldsymbol{I}-\boldsymbol{U}_{\boldsymbol{i}}\right)$ \\
\hline 1 & $1-2-4-6$ & $2 \mathrm{t}$ & $0.14 \delta_{\text {open }}$ & 0 & $0.135 \delta_{\text {open }}$ & $0.3 \delta_{\text {open }} \mathrm{t}$ \\
\hline 2 & $1-2-4-5$ & $2 \mathrm{t}+5$ & $0.27 \delta_{\text {open }}$ & 0.5 & $0.135 \delta_{\text {open }}$ & $0.3 \delta_{\text {open }} \mathrm{t}+0.67 \delta_{\text {open }}$ \\
\hline 3 & $1-7$ & $\mathrm{t}+30$ & 0.93 & $0.3 \delta_{\text {open }}$ & $0.93-0.27 \delta_{\text {open }}$ & $(\mathrm{t}+30)\left(0.93-0.27 \delta_{\text {open }}\right)$ \\
\hline 4 & $1-3-4-6$ & $2 \mathrm{t}+30$ & $0.14 \delta_{\text {open }}$ & 1 & 0 & 0 \\
\hline 5 & $1-3-4-5$ & $2 \mathrm{t}+35$ & $0.27 \delta_{\text {open }}$ & 1 & 0 & 0 \\
\hline
\end{tabular}

It may be seen that while the overall reliability is independent of $\delta_{\text {open }}, \delta_{\text {open }}$ appears on all the shortest paths and influences the overall expected shortest time $t_{\text {shortest }}$ for fire spread from the store to the ward which is given by;

$$
t_{\text {shortest }}=\left(1+0.35 \delta_{\text {open }}\right) t_{\text {flashover }}+\left(30-7.9 \delta_{\text {open }}\right) \text { minutes }
$$

\section{(iv) Protection as specified in FIRECODE}

Finally, it is worth evaluating the level of fire protection recommended in FIRECODE [3], whereby both the store room and ward doors are 30 minutes fire resisting and held on self-closing devices. For simplicity it is assumed that both self closers are equally effective and may be assigned the variable $\delta_{\text {open }}$ to represent the probability of them being open in the event of a fire.

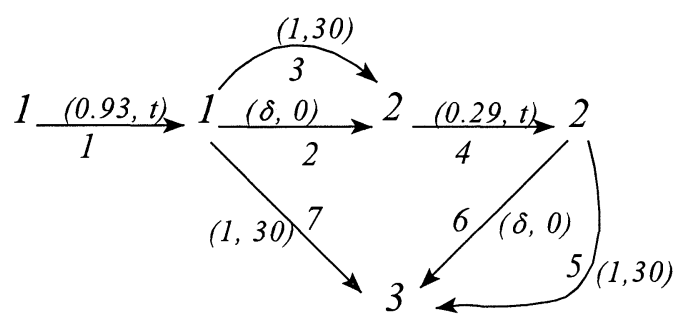

Figure 6. Probabilistic network

The probabilistic network is shown in Figure 6 and it may be readily shown that the overall expected shortest time for fire spread from the store to the ward is simply an extension of the case described in Equation (11) and is given by; 


$$
t_{\text {shortest }}=\left(1+0.35 \delta_{\text {open }}^{2}\right) t_{\text {flashover }}+\left(30-7.9 \delta_{\text {open }}^{2}\right) \text { minutes }
$$

It should be remembered at this stage that $t_{\text {shortest }}$ represents the expected shortest time for the entire network. Thus the parameter includes probabilistic effects and is not simply an identification of the individual shortest path through the network. Equation 12 demonstrates that the overall level of safety is very sensitive to the effectiveness of the door closers, clearly illustrating the benefit of adopting general house keeping measures which help to reduce the probability of the door being open.

\section{DISCUSSION}

For situations where time to flashover is small, say 5 minutes, the model suggests that the expected shortest times for the fire to spread between the store room and the ward range between 27 minutes and 35 minutes, depending on the specification of the intervening doors. The limit of 30 minutes is imposed by the fire rating of the partition directly between the ward and the store. However, the influence of the partition's fire rating could also be included in the analysis simply by adding more links between nodes 1 and 3 with an appropriate range of times and probabilities. Although specific to the scenario developed, the method has allowed the influence of four different fire protection strategies to be quantified. The findings are summarised in Table 5 , where a safety factor has been defined as the increase in the expected shortest time of fire spread compared to the datum case.

Table 5. Summary of findings

\begin{tabular}{|l|c|c|}
\hline \multicolumn{2}{|c|}{ FIRE SAFETY MEASURE } & \multicolumn{2}{|c|}{$\boldsymbol{t}_{\text {shortest }}$ (mins) } \\
\cline { 2 - 3 } & $T_{\text {fashover }}=5$ & Safety factor \\
\hline $\begin{array}{l}\text { Datum } \\
\text { 30 minute wall,5 minute doors, 50/50 chance of being open }\end{array}$ & 27.7 & 1.00 \\
\hline (i) Lock store room door & 30.0 & 1.08 \\
\hline (ii) Lock store room door, s/c on ward door & 30.4 & 1.10 \\
\hline (iii) Store room door 30 min FR, s/c on store room door & 33.7 & 1.22 \\
\hline $\begin{array}{l}\text { (iv) Firecode } \\
\text { 30 min FR doors both with s/c }\end{array}$ & 34.8 & 1.25 \\
\hline
\end{tabular}

(Note: $\mathrm{s} / \mathrm{c}=$ self-closer assumed to ensure the door is closed $80 \%$ of time; FR = fire-resisting)

The data presented in Table 5 can be used to inform decisions regarding the cost benefit of fire safety precautions. For example, while reassuringly the level of safety achieved by full compliance with the recommendations of FIRECODE [3] is some $25 \%$ higher than provided by the minimal datum level of protection, a significant increase (22\%) could be achieved simply by 
fitting a reasonably effective self-closing device on the store room door and affording it a 30 minutes fire resistance rating. The analysis also suggests that were the store room door locked shut, there is little extra benefit accrued from specifying a self-closer on the ward door. Information of this type allows the economy of each of the fire protection measures specified to be evaluated, despite the fact that there is little firm data regarding the various probabilistic components of the network.

\section{CONCLUSION}

Some very simple examples have illustrated that probabilistic networks could provide a very useful tool to aid decision making in the specification of fire protection. It could be particularly valuable in the conduct of cost benefit studies, the assessment of trade-offs and the provision of protection in circumstances where for some reason full compliance with FIRECODE [3] is not possible. The utility of the method is not unduly restricted by the absence of probabilistic data on individual components of the scenario as useful conclusions can be deduced by a combination of sensitivity analysis and engineering judgement.

\section{REFERENCES}

1. Beard, A., Applying fault tree analysis to the Coldharbour hospital fire, Fire, March,1979

2. Ling W.C.T. and Williamson R.B., Modeling of fire spread through probabilistic networks, Fire Safety Journal, 9, 1993, 287 - 300.

3. FIRECODE, NHS Estates, Department of Health, HMSO, UK

4. Charters D.A., Quantified assessment of hospital fire risks, Interflam ' 96 Conference Proceedings, Interscience Communications, 1996, UK

5. Charters D.A. and Smith F. M., The effects of materials on fire hazards and fire risk assessment, Warrington: AEA Technology, C438/017, 1992, UK

6. FIRECODE Fire Practice Note 9, NHS Healthcare fire statistics 1994/95, HMSO, 1996

7. Fire Statistics United Kingdom 1993, Home Office, 1996, UK

8. Health Facilities Note 9; Fire safety - cost or benefit ? HMSO, 1995, UK

9. Malcolm D.G., Oper. Res., 7, 1959, 646 - 669

10. Mirchandani P.B., Comput. Oper. Res., 3, 1976, 347 - 355 
